Check for updates

Cite this: Metallomics, 2020, 12, 1822

Received 26th August 2020,

Accepted 22nd October 2020

DOI: $10.1039 / \mathrm{d} 0 \mathrm{mt} 00199 f$

rsc.li/metallomics

\section{Human placental cell line HTR-8/SVneo accumulates cadmium by divalent metal transporters DMT1 and ZIP14 $\dagger$}

\author{
Raimund Widhalm, (D) ab Isabella Ellinger, (D) ${ }^{c}$ Sebastian Granitzer, ${ }^{\text {ab }}$ \\ Martin Forsthuber, (D) ${ }^{b}$ Robert Bajtela, ${ }^{\text {ab }}$ Katharina Gelles, ${ }^{c}$ Pia-Yael Hartig, ${ }^{c}$ \\ Markus Hengstschläger, ${ }^{b}$ Harald Zeisler, (D) ${ }^{d}$ Hans Salzer ${ }^{\text {ae }}$ and \\ Claudia Gundacker (iD *b
}

\begin{abstract}
Cadmium (Cd) is a global pollutant that accumulates in the placenta and can cause placental dysfunction. Although iron transporters have been suggested to participate in placental $\mathrm{Cd}$ uptake, it is still unknown which transporters are actually involved in this process. We specifically aimed to study the role of three iron transporters in the uptake of Cd into the placental cell line HTR-8/SVneo. For this purpose, Divalent Metal Transporter (DMT)1 and ZRT/IRT like protein (ZIP)8 and ZIP14 were downregulated and changes in cellular $\mathrm{Cd}$ levels analysed in relation to controls. As clearly shown by the reduction of the $\mathrm{Cd}$ content by $\sim 60 \%$ in DMT1- and ZIP14-downregulated cells, the two proteins are essential for Cd accumulation in HTR-8/SVneo cells. Using a validated antibody, we show DMT1 to be localised in situ in trophoblast and stromal cells. We further wanted to investigate how placental cells cope with Cd loading and which metallothionein (MT) isoforms they express. Cd-exposed cells accumulate $\mathrm{Cd}$ in a dose-dependent manner and upregulate MT2A accordingly (up to 15-fold induction upon $5 \mu \mathrm{M} \mathrm{CdCl}_{2}$ treatment for $72 \mathrm{~h}$ ). $5 \mu \mathrm{M}$ Cd exposure for $72 \mathrm{~h}$ decreased cell number to $60 \%$, an effect that was aggravated by MT2A depletion (cell number reduced to $30 \%$ ) indicating additive effects. In conclusion, our data suggest that DMT1 and ZIP14 are required for Cd uptake into human placental cells that upregulate MT2A to store and detoxify the metal. Cd storage in the placenta reduces $\mathrm{Cd}$ transport to the fetus, which, however, could impair placental functions and fetal development.
\end{abstract}

Significance to metallomics

$\mathrm{Cd}$ accumulates in the human placenta, which can be harmful to the organ. Our knowledge about placental Cd transport is very fragmentary. We have attempted to clarify crucial points, namely which transporters mediate the uptake of $\mathrm{Cd}$ into the placental cells and how the cells retain Cd. We show that iron/zinc transporters are involved and that placental cells upregulate metallothionein (MT)2A to detoxify the metal. Iron and/or zinc deficiency during pregnancy in combination with increased Cd exposure and genetically reduced placental MT2A function are risk factors for adverse pregnancy outcomes that should be further investigated.

\section{Introduction}

The heavy metal cadmium (Cd) is a ubiquitous pollutant of great importance to public health and has been identified as a priority substance by regulatory authorities and public health

\footnotetext{
${ }^{a}$ Karl-Landsteiner Private University for Health Sciences, Krems, Austria

${ }^{b}$ Institute of Medical Genetics, Medical University Vienna, Waehringer Strasse 10, A-1090 Vienna, Austria. E-mail: claudia.gundacker@meduniwien.ac.at; Fax: +43140160 956501; Tel: +43140160 56503

${ }^{c}$ Institute for Pathophysiology and Allergy Research, Medical University Vienna, Austria

${ }^{d}$ Department of Obstetrics and Gynecology, Medical University Vienna, Austria

${ }^{e}$ Clinic for Pediatrics and Adolescent Medicine, University Hospital Tulln, Austria

$\dagger$ Electronic supplementary information (ESI) available. See DOI: 10.1039/d0mt00199f
}

authorities worldwide, ${ }^{1-3}$ a large-scale research initiative in Europe, ${ }^{4}$ and the World Health Organization. ${ }^{5}$

Since its discovery in the beginning of the 19th century, Cd toxicity became apparent in exposed workers, but it took over 100 years to investigate its toxicological properties. In the early 20th century, it was discovered that Cd affects tissues differently (with first reports from Cd damaged lungs in the 1930s, while reports on the placenta emerged in the 1960s), and about 20 years later its major interaction partner, metallothionein (MT), was identified. However, only recent advancements in biomedical research over the last three decades led to the identification of transporters that may help our understanding of how Cd enters these tissues (in our case the placenta) and exerts its harmful properties (Fig. 1A). ${ }^{6-13}$ 
During pregnancy, the developing child is protected from Cd exposure by the placenta. The human placenta is a transient organ providing the interchange of gases and nutrients

between mother and child. The placental barrier, the placental
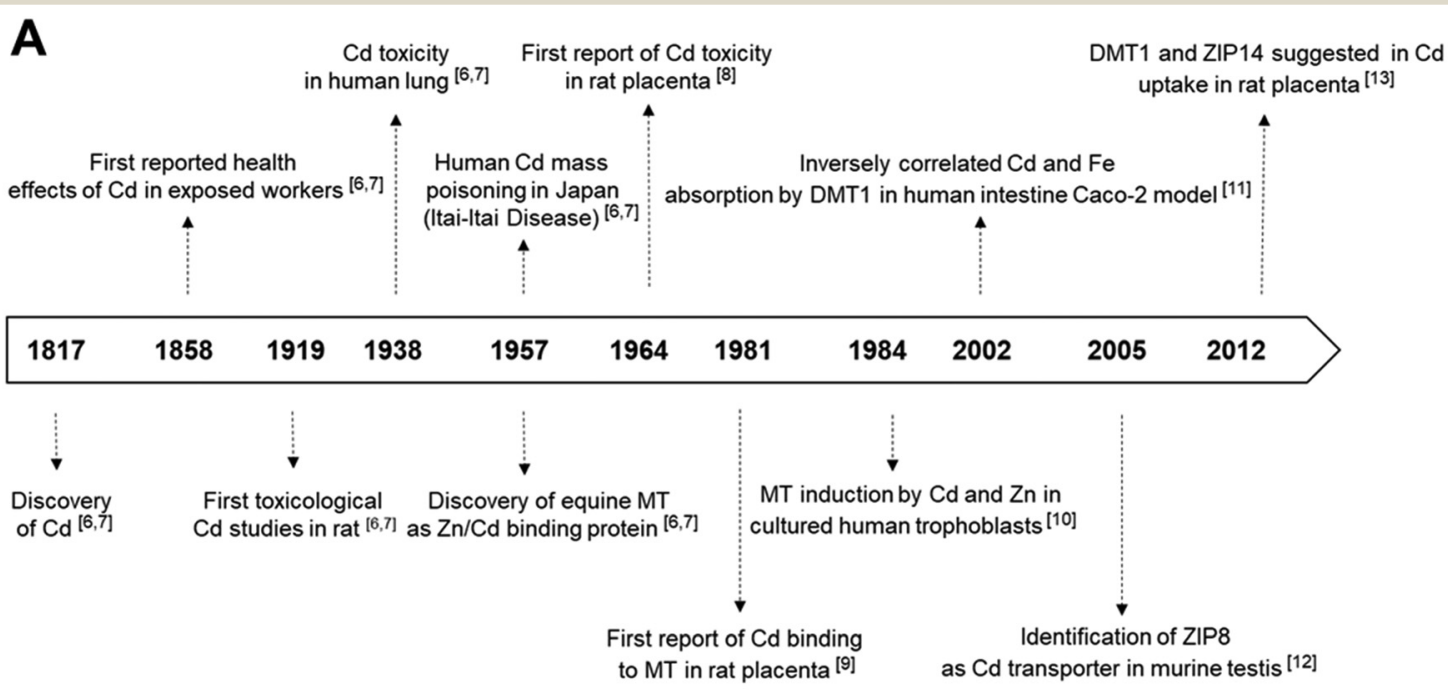

B

DMT1

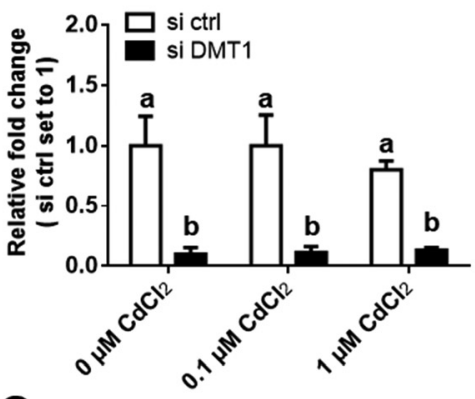

,

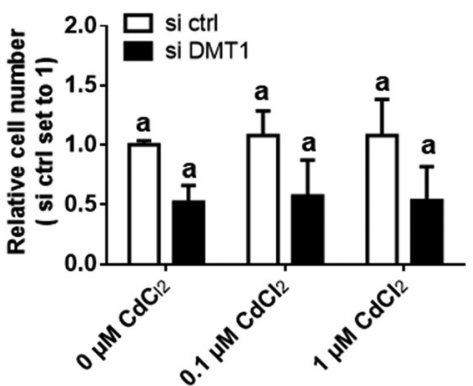

D
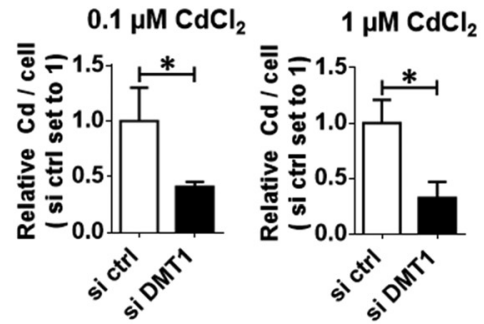
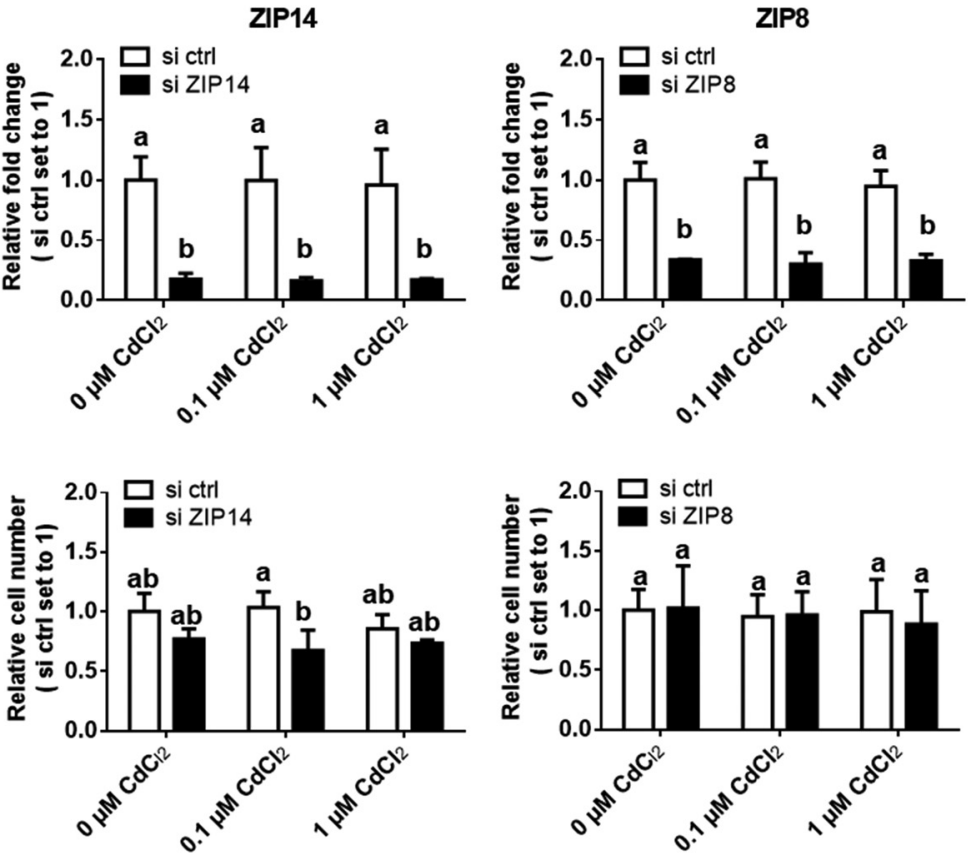

Fig. 1 Involvement of DMT1, ZIP14 and ZIP8 in cellular Cd accumulation. (A) Timeline of major scientific discoveries in the field. (B) Knockdown efficiency was confirmed for each target and treatment condition by GPCR. (C) Mean cell number was determined for each target and treatment by CASY ${ }^{\circledR}$ cell counter. (D) Cellular Cd levels are given for DMT1, ZIP14 and ZIP8 depleted cells and control cells both treated with 0.1 or $1 \mu$ M CdCl ${ }_{2}$ for $24 \mathrm{~h}$. Control cells (si ctrl) treated with $0 \mu \mathrm{M} \mathrm{CdCl}_{2}$ was set to 1 . The data represent mean values $\pm \mathrm{SD}$ from three independent experiments made in six technical replicates. The letters $\mathrm{a}$ and $\mathrm{b}$ denote homogeneous subgroups derived from one-way ANOVA and $\mathrm{S}-\mathrm{N}-\mathrm{K} p o s t h o c$ test $(p<0.05) ;{ }^{*} p<0.05$, ${ }^{* \star} p<0.01,{ }^{* \star} p<0.001$, n.s. $=$ non-significant from students $t$-test. 
exchange surface over which substance transfer takes place, consists of the outlying syncytiotrophoblast (STB) that is in direct contact with the maternal blood, the underlying cytotrophoblast (CTB) that becomes discontinuous in later pregnancy, and the placental fetal endothelial cells (pFECs). ${ }^{14}$ In contrast to other heavy metals like mercury, which can readily cross the placenta, $\mathrm{Cd}$ is efficiently retained in the placenta. ${ }^{15}$ However, the major storage sites for Cd are still kidney and liver (up to $84 \mu \mathrm{g} \mathrm{g}^{-1}$ and $13 \mu \mathrm{g} \mathrm{g}^{-1}$ in comparison to up to $0.053 \mu \mathrm{g} \mathrm{g}^{-1}$ found in placenta). ${ }^{16-19}$ It has been proposed that $\mathrm{Cd}$ induces placental expression of MTs that scavenge $\mathrm{Cd}$ and thereby reduce its transfer to the fetal side. ${ }^{20,21}$ Thereby, continuous Cd exposure during pregnancy leads to $\mathrm{Cd}$ accumulation in placental tissue causing structural and functional abnormalities including reduced trophoblast proliferation rates, ${ }^{22}$ sex-specific alteration of DNA methylation patterns ${ }^{23}$ and changes of (micro)nutrient transport. ${ }^{21}$ Although placental retention of Cd protects the fetus from Cd-associated developmental toxicity, ${ }^{23}$ the metal can impair placental function and thus indirectly have negative effects on offspring. Consequently, prenatal Cd exposure has been reported to be associated with increased risk for preterm birth, ${ }^{24}$ reduced birth weight ${ }^{25}$ and pre-eclampsia. ${ }^{26}$

How Cd enters the human placenta is not known and specific transporters for the non-essential metal do not exist. Iron transporters that also transport other divalent metal ions are likely candidates for the placental transport of $\mathrm{Cd}^{15,27}$ and an inverse relationship between $\mathrm{Cd}$ and iron transport has been suggested. ${ }^{11,28,29}$ The candidate transporters with high affinity to $\mathrm{Cd}$ include the Divalent-Metal Transporter (DMT)1 (SLC11A2), ${ }^{30}$ the ZRT/IRT-like Protein (ZIP)8 (SLC39A8) ${ }^{31}$ and ZIP14 (SLC39A14). ${ }^{32}$ While it seems clear that DMT1 mediates the intestinal uptake of Cd, ${ }^{11,33-37}$ ZIP8 and ZIP14 have been reported for Cd transport in kidney, testis and liver. ${ }^{38}$ Regarding the human placenta, information on cellular influx/efflux of Cd through iron transporters is virtually non-existing. Only an upregulation of DMT1 and ZIP14 mRNA in placentas of Cd exposed rat dams and DMT1 mRNA in placentas of highly Cd exposed women has been described so far. ${ }^{13,39}$

In view of the many gaps in knowledge, the aims of the present study were (1) to investigate the role of iron transporters DMT1, ZIP8 and ZIP14 in Cd uptake of placental cell line HTR-8/SVneo. ${ }^{40} \mathrm{We}$ hypothesized that upon siRNA-mediated knockdown of the respective transporter, cellular Cd levels should be decreased in comparison to control cells. (2) We also wanted to address the in situ localisation of the involved transporters in placental sections by immunofluorescence microscopy. After establishing which transporters mediate placental Cd uptake and where they are localised in the tissue, our aim was (3) to determine how cells can cope with Cd burdens, probably by $\mathrm{MT}^{41}$ to bind and detoxify the metal.

\section{Materials and methods}

\section{Cell culture}

HTR-8/SVneo cells (ATCC, CRL-3271 ${ }^{\mathrm{TM}}$, Lot\# 64275781) were cultured at $37{ }^{\circ} \mathrm{C}$ and $95 \%$ air/5\% $\mathrm{CO}_{2}$ in RPMI 1640 medium
(Gibco) that contained 5\% fetal bovine serum (FBS; PanBiotech) and 1\% GlutaMax (Gibco). When they had reached confluence, cells were dissociated from the culture dish using Accutase (Sigma). The cell number was determined with a CASY cell counter and analyzer (CASY ${ }^{\circledR}$ Model TTC 45/60/150, Innovatis Technologies Inc.). All cells were periodically checked for Mycoplasma contamination (MycoAlert; Lonza). HTR-8/SVneo cells from passages 90 to 100 were used in the experiments.

\section{Cd dosages}

Aqueous Cd stock solutions were made from Cd(II)-chloride $\left(\mathrm{CdCl}_{2}\right)(\mathrm{Merck})$. The selection of the concentrations $0.1,1$ and $5 \mu \mathrm{M} \mathrm{CdCl}{ }_{2}$ were based on previous reports on cytotoxic effects of $\mathrm{Cd}^{42,43}$ and further selected for methodological reasons, i.e., to ensure detectability of cellular Cd after $24 \mathrm{~h}$ treatment. In preparatory experiments as well as for the determination of lethal concentration (LC)50, also higher Cd concentrations up to $20 \mu \mathrm{M}$ were used.

\section{Knockdown experiments}

Cells were seeded in 6 -well plates $\left(1 \times 10^{5}\right.$ cells per well $)$ or 12 well plates $\left(5 \times 10^{4}\right.$ cells per well) and upon reaching $25-35 \%$ confluence transiently transfected with non-targeting siRNA (control cells) and siRNA specifically targeting MT2A, SLC11A2, SLC39A8 and SLC39A14 (encoding MT2A, DMT1, ZIP8, and ZIP14 respectively) (GE Dharmacon) using Lipofectamine RNAimax (Life Technologies) as described previously. ${ }^{44}$ Upon knockdown cells were cultured for $48 \mathrm{~h}$ and then incubated with standard medium containing $0.1,1$ and $5 \mu \mathrm{M} \mathrm{CdCl}_{2}$ for up to $72 \mathrm{~h}$.

\section{Cd dependent MT2A expression}

Cells were seeded in 6 -well plates $\left(1 \times 10^{5}\right.$ cells per well), upon reaching $\sim 70 \%$ confluence treated with $0,0.1,0.25,0.5,0.75,1$, 2.5, $5 \mu \mathrm{M} \mathrm{CdCl}_{2}$ and harvested after 24,48 and $72 \mathrm{~h}$.

\section{RNA isolation, cDNA synthesis and quantitative PCR (qPCR)}

Total RNA was isolated with TRI Reagent ${ }^{\circledR}$ (Sigma), following manufacturer's instructions and reversely transcribed with GoScript Reverse Transcription System (Promega) using random hexamer primers. The cDNA was diluted $1: 10$, and $2 \mu \mathrm{L}$ were used as a template in a $15 \mu \mathrm{L}$ reaction to assay gene expression in an Applied Biosystems StepOnePlus ${ }^{\mathrm{TM}}$ Real-Time PCR System, according to the manufacturer's protocol. The employed primers are listed in Table S1 (ESI $\dagger)$.

\section{Protein extraction and immunoblotting}

Placental tissue (Department of Obstetrics and Gynecology, Medical University Vienna; EK 724/2010) was lysed in Tissue Protein Extraction Reagent (Thermo Scientific) buffer containing 1\% proteinase inhibitor (Thermo Scientific) and 1\% EDTA (Thermo Scientific).

Cells were lysed in RIPA Buffer (Thermo Scientific) supplemented with 0.5 M EDTA solution (Thermo Scientific) and Halt ${ }^{\mathrm{TM}}$ Protease and Phosphatase Inhibitor (Thermo Scientific). 10-15 $\mu \mathrm{g}$ total protein was separated via 10 and 12.5\% SDS-PAGE and 
transferred onto nitrocellulose membranes. Blots were blocked for $1 \mathrm{~h}$ in Odyssey Blocking Buffer (TBS) (LI-COR), followed by incubation with Odyssey Blocking Buffer (TBS) containing 0.1\% Tween and the primary antibody over night at $4{ }^{\circ} \mathrm{C}$. On the next day, blots were washed and incubated with the corresponding fluorophore-conjugated antibody for $1 \mathrm{~h}$ at room temperature. Near-Infrared Fluorescence (NIR) was detected with the Odyssey CLx imager (LI-COR) using Image Studio Lite 5.2 software. Total protein was stained using REVERT $^{\mathrm{TM}}$ Total Protein Stain (LI-COR). Employed primary antibodies for DMT1 (Cell Signaling, 15083), ZIP14 (Invitrogen, PA5-87880) and $\alpha$-tubulin (Sigma Aldrich, CP06) were diluted 1:1000 if not stated otherwise. Fluorophore-conjugated antibodies for NIR (IRDye ${ }^{\circledR}$ 800CW Goat anti-Mouse IgG1-Specific, LI-COR, 926-32350; IRDye $^{\circledR}$ 800CW Goat anti-Rabbit IgG Secondary Antibody, LI-COR, 926-32211) were diluted 1:20000 if not stated otherwise.

\section{Cd analysis with graphite furnace atomic absorption spectroscopy (GF-AAS)}

Cell pellets and reference material (Seronorm Trace Elements Whole Blood L-2; Lot\#1702825) were acid-digested with nitric acid (69\%; Suprapur ${ }^{\circledR}$, Carl Roth) in a microwave oven (MARS6, CEM Corporation) and analysed by GF-AAS (Zeenit 700P, Analytik Jena). The mean level of the reference material $\left(5.2 \pm 0.8 \mu \mathrm{g} \mathrm{L}^{-1}\right.$; $N=10)$ lay well within the certified range $\left(4.1-6.1 \mu \mathrm{g} \mathrm{L}^{-1}\right)$. The limit of detection (LOD) was $0.0426 \mu \mathrm{g} \mathrm{\textrm {L } ^ { - 1 }}$. All samples were measured three times by the working curve method (RSD $<15 \%$ ).

\section{Immunofluorescence microscopy (IFM)}

Human placental tissue $(N=5)$ was obtained within 15 minutes after caesarian sections of healthy pregnancies at 38-40 weeks of gestation (Department of Obstetrics and Gynecology, Medical University Vienna; EK 724/2010). The tissues were transferred to the laboratory at room temperature within $15 \mathrm{~min}$. For IFM, chorionic tissue was immediately processed by HOPE-fixation (DCS Innovative Diagnostik-Systeme) and paraffin-embedding. $4 \mu \mathrm{m}$ tissue sections were de-waxed and rehydrated. Antigen retrieval was done with $0.05 \%$ (v/v) citraconic anhydride solution, $\mathrm{pH} 7.4$, for $20 \mathrm{~min}$. Sections were incubated with $5 \%(\mathrm{v} / \mathrm{v})$ goat serum (Jackson ImmunoResearch Laboratories) in PBS containing $0.05 \%(\mathrm{w} / \mathrm{v})$ saponin (Sigma) for $1 \mathrm{~h}$ at room temperature (blocking buffer). Primary antibodies and corresponding Alexa-Fluor ${ }^{\mathbb{R}}$-conjugated secondary antibodies, diluted in blocking buffer, were applied overnight at $4{ }^{\circ} \mathrm{C}$ or for $2 \mathrm{~h}$ at room temperature, respectively. In negative control incubations, primary antibodies were omitted. Nuclei were stained with DRAQ5 (Thermo Scientific; $25 \mu \mathrm{M}$ in PBS). After each incubation step, sections were washed intensively with PBS. Antibodies were added consecutively. Fluoromount-G (SouthernBiotech) was used as mounting medium. Images were acquired using an automated wide-field fluorescence microscope (Axio Imager Z1, Zeiss), equipped with an $63 \times / 1.4$ oil objective (Plan-Apochromat, Zeiss) and the following filter sets (Chroma Technology Corp.): 49002 ET-FITC/Cy2, 49008 ET-mCherry, TxRed and 49006 ET-Cy5 in combination with TissueFAXS Image Acquisition and Management Software (Version 4.2; TissueGnostics $\mathrm{GmbH}$ ). Using a monochrome camera (Hamamatsu), grayscale images of individual fluorescence channels were acquired. Thereafter, pseudocolors were assigned to the channels and individual combinations of channels were merged. Images were further processed by Adobe Photoshop.

Primary antibodies used were rabbit anti-DMT1 (Cell Signaling, 15083S, IFM dilution 1:50), mouse anti-CD31 (Dako, M0823, clone JC70A, IFM dilution 1:200); mouse anti-Cytokeratin 7 (CK7), (Dako, M7018, clone OV-TL 12/30, IFM dilution 1:200), and mouse anti-CD68 (Dako, M0876, clone PG-M1, IFM dilution 1:100). Secondary antibodies used were Alexa Fluor 568 (A-11011)-conjugated goat anti rabbit IgG and Alexa Fluor 488 (A-11001)-conjugated goat anti-mouse IgG (all Life TechnologiesMolecular Probes, IFM dilution 1:2000).

\section{Phase contrast microscopy}

Photographs were taken 24, 48 and 72 h after indicated treatment with an inverted fluorescence and phase contrast tissue culture microscope (OLYMPUS IX51) equipped with an Olympus UPlanFLN $4 \times / 0.13 \mathrm{Phl} / \infty /$-/FN 26.5 objective. Pictures were processed using Olympus cellSens Standard 2.2 software.

\section{Statistics}

Data represent mean values \pm standard deviation (SD) from three independent experiments (different passages of HTR-8/ SVneo cells) made in three to six technical replicates. Two group comparisons were done by two-sided unpaired $t$-test. For the comparison of group differences between more than two groups, data were ranked, and One-way ANOVA was applied, followed by Student-Newman-Keuls (S-N-K) post hoc test to correct for multiple testing. Spearman correlation analysis was used to determine the relationships between cellular Cd and MT2A levels. We used GraphPad Prism 6, MS Excel and IBM SPSS 21 software. The critical significance level was set at $\alpha=0.05$.

\section{Results and discussion}

\section{DMT1 and ZIP14, but not ZIP8 mediate Cd uptake in HTR-8/SVneo cells}

To verify their function, the candidate proteins DMT1, ZIP14 and ZIP8 were depleted in HTR-8/SVneo cells by siRNAmediated gene knockdown. The efficiency of the respective gene knockdown, which resulted in a reduction of mRNA levels to $20-30 \%$, was verified by qPCR (Fig. 1B). The mRNA levels of the transporters (Fig. 1B) as well as the cell number (Fig. 1C) were unaffected by Cd exposure of 0.1 and $1 \mu \mathrm{M}$ within $24 \mathrm{~h}$. This is consistent with previous reports that showed $\mathrm{Cd}$ to induce DMT1, ZIP8 and ZIP14 mRNA expression as well as causing antiproliferative effects only at doses greater than $5 \mu \mathrm{M}^{45,46}$

Cellular Cd levels decreased upon DMT1 and ZIP14 knockdown to about $40 \%$ respectively, an effect not seen for ZIP8 depleted cells (Fig. 1D). It was obvious that DMT1 could also be a candidate for $\mathrm{Cd}$ transport at the human placental barrier. ${ }^{13,40}$ Although we expected DMT1 to be the most important Cd 
transporter, ZIP14 depletion brought similar results concerning Cd uptake into placental cells. As mentioned above, ZIP14 can transport Cd efficiently, but for the placenta we only know so far that it is expressed in rat $^{13}$ and human, ${ }^{47}$ but not what function it has. While it is likely that the function of ZIP14 in the placenta is iron or zinc transport, ${ }^{48}$ to our knowledge we are the first to demonstrate a Cd transporting role of ZIP14 for placental cells.

Regarding ZIP8, the results came as a surprise. Among 20 different human tissues and right after the lung, it was described that the placenta has the highest mRNA expression of ZIP8. ${ }^{31}$ The irrelevance of ZIP8 for Cd uptake into placental cells was unexpected in that the transporter has been shown to have the highest substrate affinity for $\mathrm{Cd} .{ }^{31}$ In addition, Cd-resistant lung epithelial cells adapt to $\mathrm{Cd}$ cytotoxicity by downregulating ZIP8 to reduce its uptake. ${ }^{49}$ Apart from the fact that $\mathrm{Cd}$ can have different effects on certain cell types, it is possible that the lack of ZIP8 can be compensated by another transporter like ZIP14 or DMT1. ${ }^{50}$

\section{In situ localisation of DMT1}

To relate the observed function of iron transporters in our cell culture model with their role in the placenta, we wanted to validate antibodies for ZIP14 and DMT1 that could be further used for in situ localisation of the proteins in the human term placenta. While a commercial ZIP14 antibody was deemed unsuitable for the proper detection of the protein (Fig. S1, ESI $\dagger$ ), we could validate another antibody to specifically detect DMT1 (Fig. S2, ESI $\dagger$ ).
It has been reported that DMT1 expression in the apical membrane of the STB is absent ${ }^{51}$ or very low. ${ }^{52}$ To our surprise, yet in well accordance with a previous ${ }^{53}$ and a very recent DMT1 localisation study, ${ }^{40}$ we found the transporter to be highly expressed throughout the STB (Fig. 2a and d) and moderately in placental macrophages (Hofbauer cells) (Fig. 2b and e) and pFECs (Fig. 2c and f). The presence of DMT1 in the STB at the apical membrane, in the pFECs and macrophages actually speaks for the involvement of the transporter in Cd uptake into these cells. The proteins that transport Cd out of the STB and then out of pFECs into fetal blood remain to be elucidated. The zinc transporter (ZnT)4 and ZnT5 that are expressed in the human placenta ${ }^{54}$ and various other transporters including ABC transporters are plausible candidates. ${ }^{55}$

Cd reaches the fetal blood in comparably small amounts ${ }^{15}$ indicating efficient retaining of the metal in placental tissue. One of the most likely intracellular binding partners of Cd is MT2A. ${ }^{41,56}$ Previous observations on Cd-induced MT2A expression in the human placenta revealed that it predominantly occurs in the stroma of the villous core. ${ }^{57}$ Together with the finding that DMT1 is expressed in trophoblast and stromal cells of the placenta, this may well explain why $\mathrm{Cd}$ accumulates in this part of the human placenta and why only small amounts of Cd are transported into fetal blood. Overall, it must be taken into account that $\mathrm{Cd}$ storage in the placenta (as Cd-MT complex) reduces $\mathrm{Cd}$ transport to the fetus, but could impair placental functions and thus fetal development for example through reduced zinc transfer across the placenta. ${ }^{21,41}$
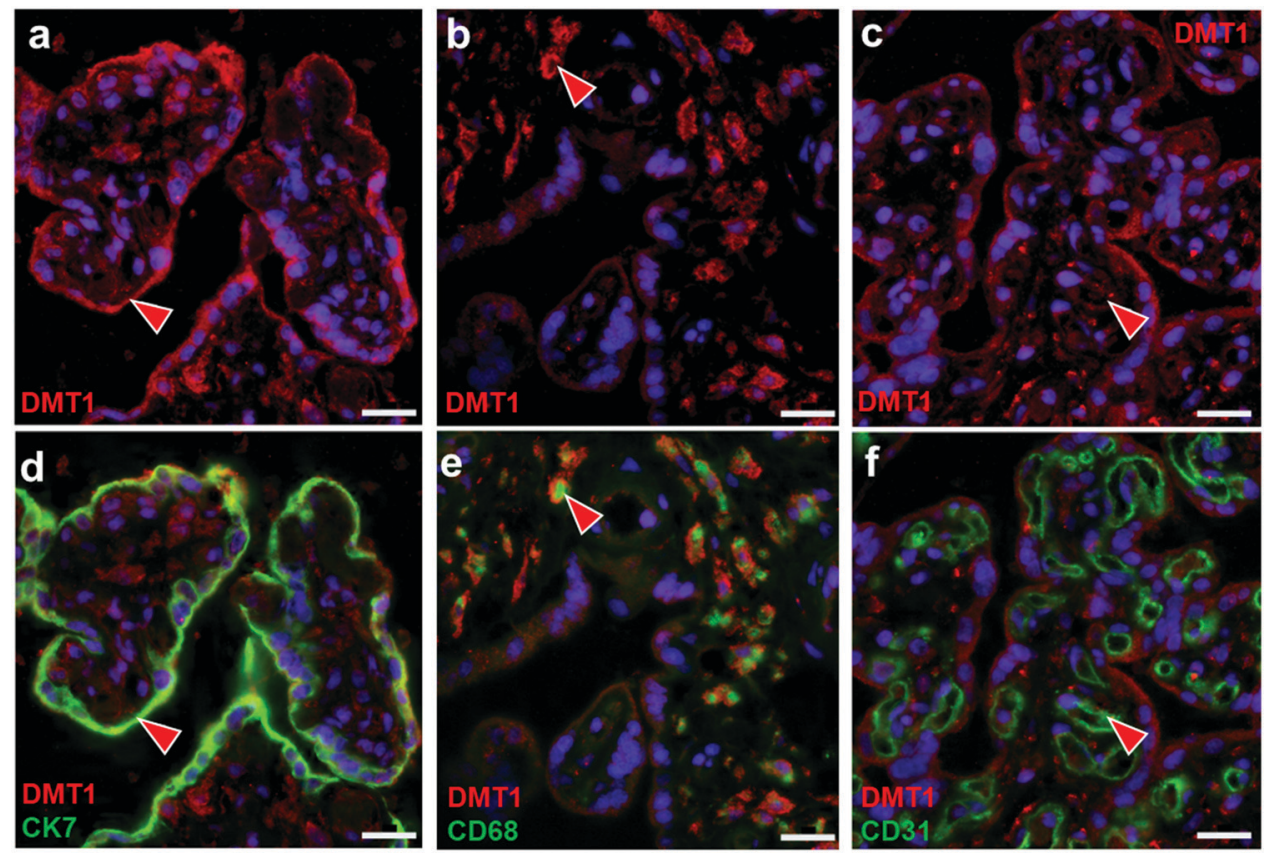

Fig. 2 Localisation of DMT1 in human term placenta. $4 \mu \mathrm{m}$ sections of HOPE-fixed and paraffin-embedded placentas were stained with specific primary and fluorescence-conjugated secondary antibodies. Localisation is shown either alone for DMT1 (red arrowhead; (a) - (c) or as a co-staining with (d) STBspecific marker Cytokeratin (CK)7 (e) macrophage-specific marker Cluster of Differentiation (CD)68 and (f) pFEC-specific marker CD31, which are shown in green, respectively). Nuclei were labelled with DRAQ5 and are shown in blue. Bars represent $30 \mu \mathrm{m}$. 


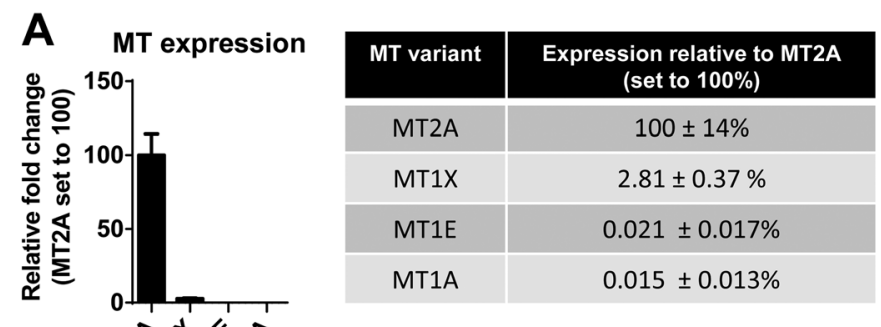

B
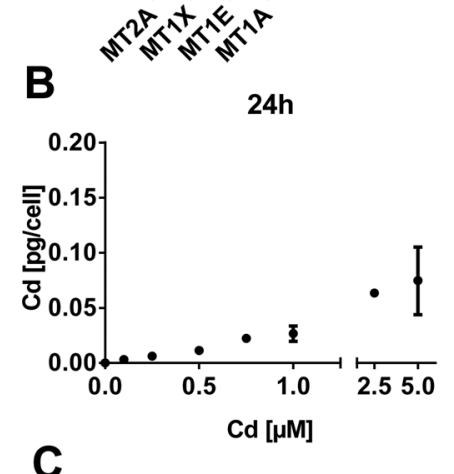

24h

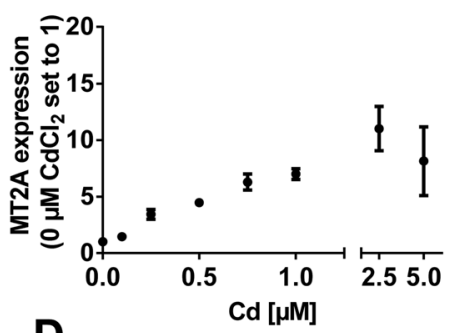

D

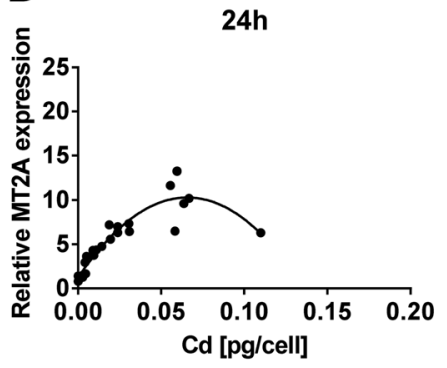

$\mathbf{E}$

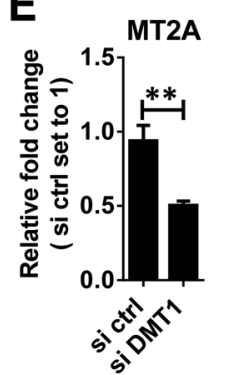

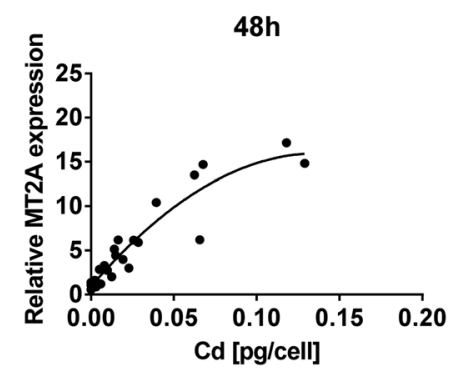

$48 h$

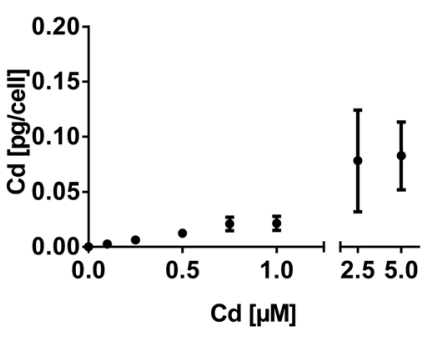

48h

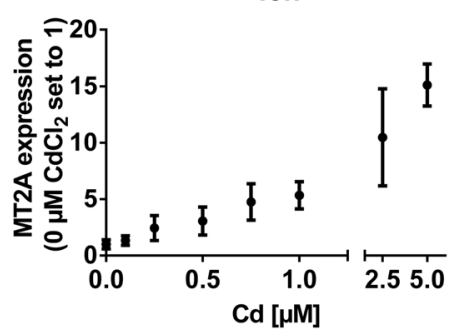

MT2A

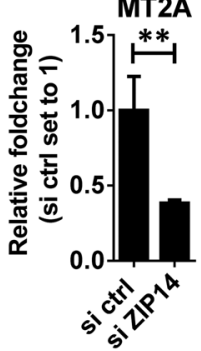

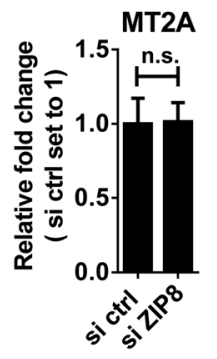

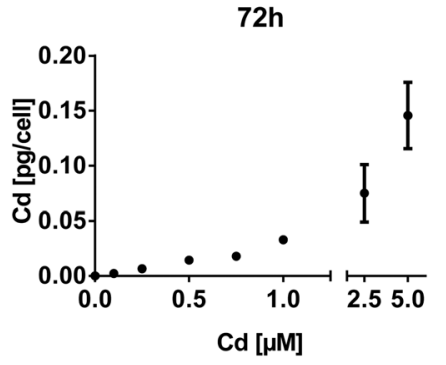

72h

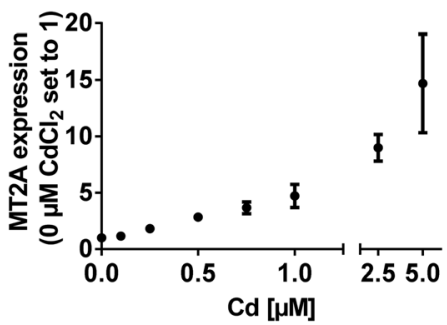

$72 \mathrm{~h}$

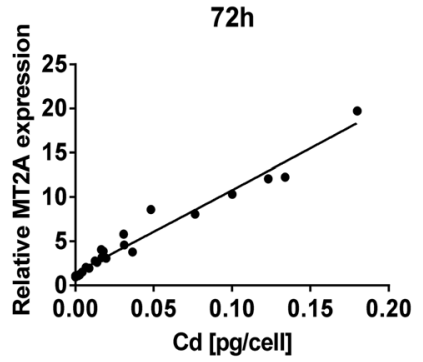

Fig. 3 MT2A expression in Cd exposed HTR-8/SVneo cells. (A) Comparison of MT1A, MT1E, MT1X expression relative to MT2A levels. (B) Cd concentration in cells treated with indicated Cd concentrations for 24,48 and $72 \mathrm{~h}$ was determined by GF-AAS. Mean cellular Cd increase was 0.10 , $0.24,0.48,0.79,2.8$ and 3.7 relative to $1 \mu \mathrm{M} \mathrm{CdCl}_{2}$ treatment for cells exposed to $0.1,0.25,0.5,0.75,2.5$ and $5 \mu \mathrm{M} \mathrm{CdCl}_{2}$. (C) MT2A expression in cells treated with indicated $\mathrm{Cd}$ concentrations for 24,48 and $72 \mathrm{~h}$ was monitored by qPCR. Mean MT2A increase was $0.21,0.34,0.52,0.73,1.81$ and 2.36 relative to $1 \mu \mathrm{M} \mathrm{CdCl}_{2}$ treatment for cells exposed to $0.1,0.25,0.5,0.75,2.5$ and $5 \mu \mathrm{M} \mathrm{CdCl}_{2}$ (D) Correlation of MT2A expression and intracellular Cd levels (Spearman correlation, $p<0.01$ ). Spearman $R^{2}$ of $0.913,0.932$ and 0.977 at $24 \mathrm{~h}, 48 \mathrm{~h}$ and $72 \mathrm{~h}$. The trend curve was adapted to a polynomial equation (E) mRNA levels of MT2A in HTR-8/SVneo cells cultured for $24 \mathrm{~h}$ in presence of $1 \mu \mathrm{M} \mathrm{CdCl}_{2}$ in controls and cells depleted for DMT1, ZIP14 or ZIP8. The data represent mean values $\pm S D$ from three independent experiments made in triplicate $(A)$ or six technical replicates $(B)-(E)$. The letters a- $h$ denote homogeneous subgroups derived from one-way ANOVA and S-N-K posthoc test $(p<0.05)$ (E) Students $t$-test. ${ }^{* *} p<0.01$. n.s. $=$ non-significant. 
A

si ctrl
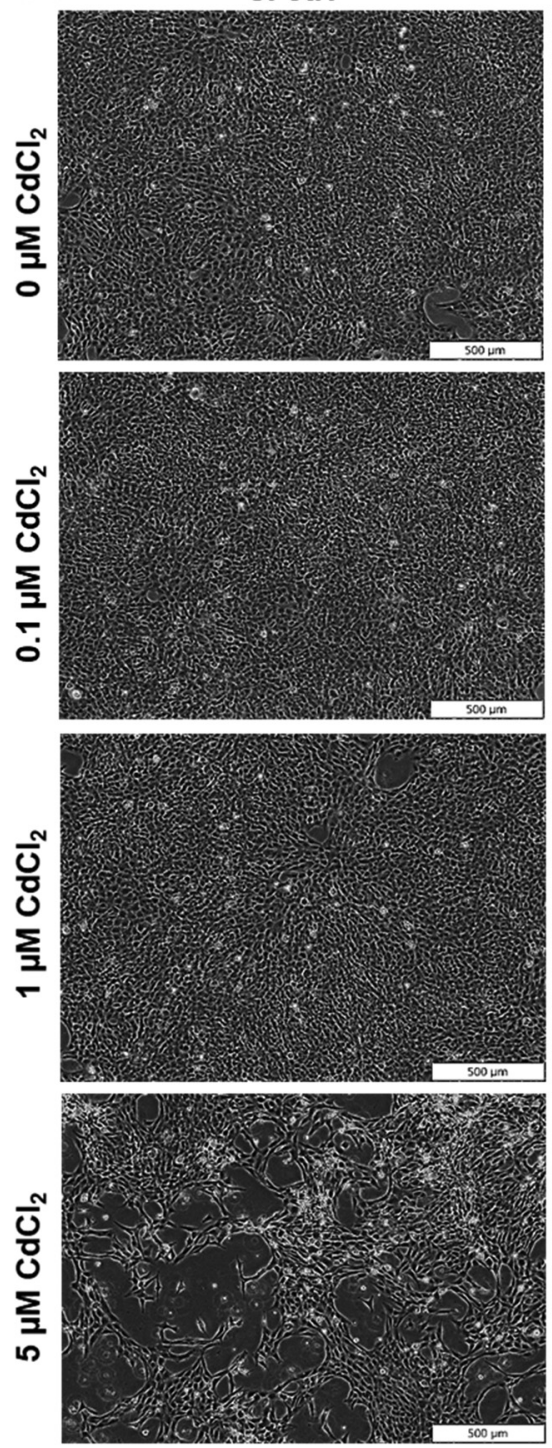

C

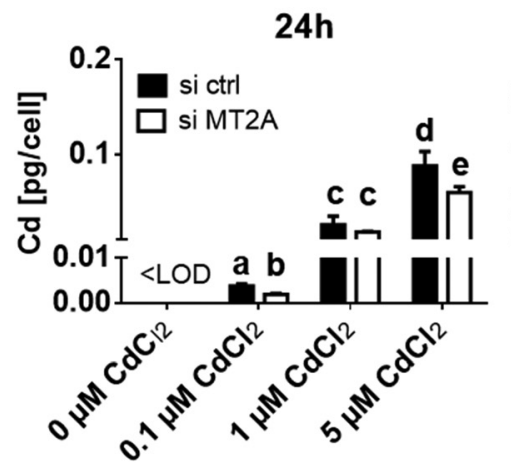

si MT2A
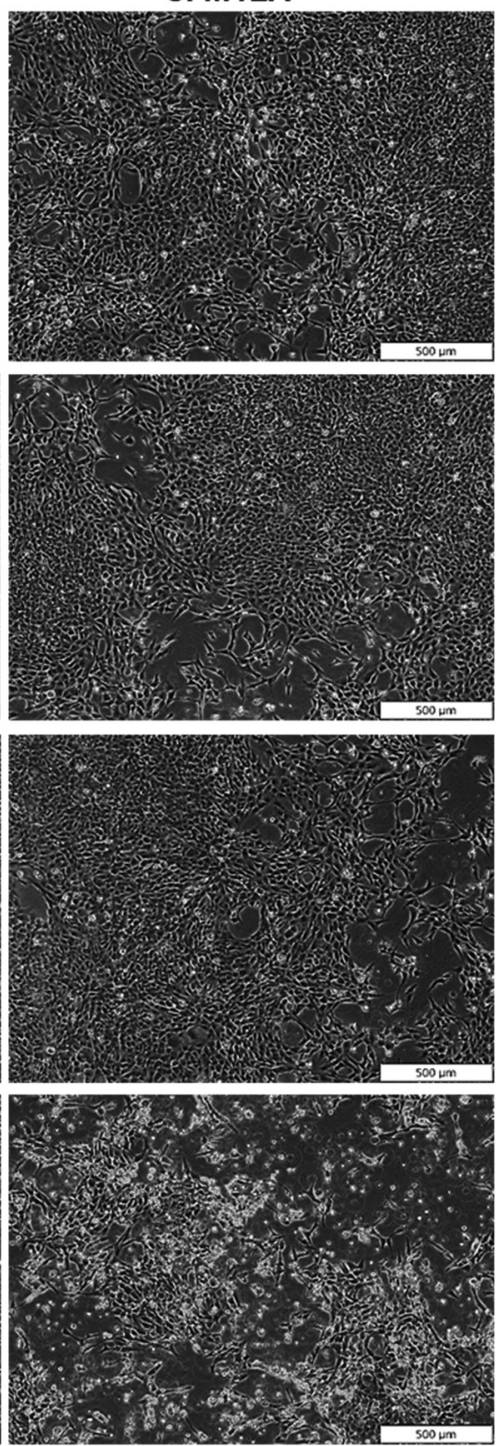

B
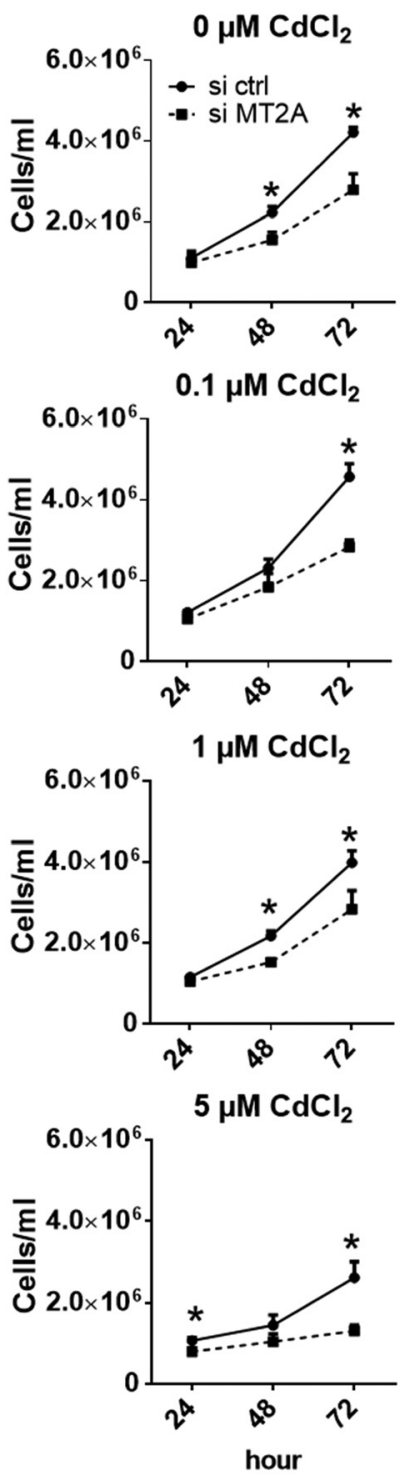

$72 h$
$48 h$
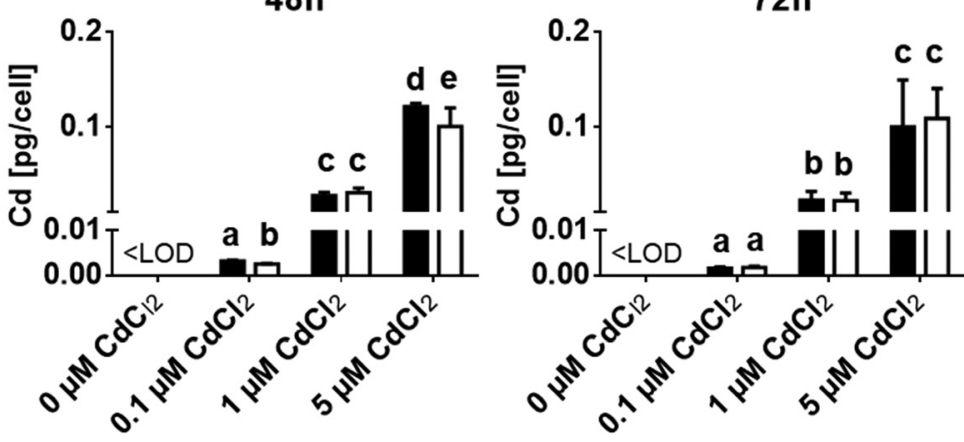

Fig. 4 Effects of $\mathrm{Cd}$ and MT2A depletion on cell number and $\mathrm{Cd}$ accumulation of HTR-8/SVneo cells. (A) Representative phase contrast images of control and MT2A knockdown cells treated with indicated Cd concentrations for $72 \mathrm{~h}$. (B) Control and MT2A depleted cells were treated with indicated Cd concentrations for 24, 48 and $72 \mathrm{~h}$ and cell number was measured by Casy ${ }^{\mathbb{R}}$ Cell Counter. (C) Cellular Cd levels of control and MT2A depleted cells that were treated 24,48 and $72 \mathrm{~h}$ with indicated $\mathrm{Cd}$ concentrations was determined by GF-AAS. The data represent mean values \pm SD from three independent experiments each made in six technical replicates. The letters a-e denote homogeneous subgroups derived from one-way ANOVA and $\mathrm{S}-\mathrm{N}-\mathrm{K}$ posthoc test $(p<0.05)$. Bar represents $500 \mu \mathrm{m}$. 


\section{MT2A protects HTR-8/SVneo cells from Cd toxicity}

MTs are cysteine-rich proteins that preferably bind divalent metal cations and thus regulate metal (predominantly zinc and copper) homeostasis in cells. Cd has a high binding affinity to MT, replacing zinc, which then activates Metal-Transcription Factor (MTF)1 to induce its downstream targets. These include MTs that in turn bind $\mathrm{Cd}$ and can thus detoxify the metal. ${ }^{58}$ From the 10 functional MT genes described in humans, MT1 (further subdivided into MT1A, -1B, -1E, -1F, -1G, $-1 \mathrm{H}$ and $-1 \mathrm{X}$ ) and MT2 (synonymous to MT2A) are the major groups. ${ }^{59}$ MT synthesis, which can be induced by several metals including $\mathrm{Cd}$, is essential for metal detoxification and the reduction of metal-induced oxidative stress. ${ }^{60}$ The susceptibility to Cd toxicity largely depends on the cell type ${ }^{61,62}$ respectively on the ability of cells to induce MT expression. ${ }^{63}$

According to our data MT2A has by far the highest expression in HTR-8/SVneo cells among the MT isoforms studied (Fig. 3A). This finding is in very good agreement with a previous report ${ }^{64}$ in which MT1X, MT1A and MT1E levels were identified at $8.5 \%, 0.001 \%$ and $0.01 \%$ of MT2A levels (we found $2.5 \%, 0.015 \%$ and $0.021 \%$ respectively) and other studies in HeLa cells, ${ }^{64}$ human urothelial cells ${ }^{65}$ and various endothelial cells ${ }^{66}$ showing that MT2A is the constitutively most strongly expressed MT form.

To prove the strong inducibility of MT2A by Cd in placental cells, we analysed cellular $\mathrm{Cd}$ concentrations and corresponding MT2A levels of Cd-treated HTR-8/SVneo. Intracellular $\mathrm{Cd}$ increased in a dose-dependent linear manner up to $2.5 \mu \mathrm{M}$ Cd treatment (Fig. 3B). MT2A expression showed a similar linear response up to $1 \mu \mathrm{M}$ Cd treatment (Fig. 3C). Accordingly, cellular Cd levels and MT2A levels correlate exceptionally well (Fig. 3D).

Another question was whether the knockdown of DMT1, ZIP8 and ZIP14 would change MT2A expression. In HTR-8/ SVneo cells treated with $1 \mu \mathrm{M} \mathrm{CdCl}_{2}, \mathrm{MT} 2 \mathrm{~A}$ levels were reduced to $\sim 40-50 \%$ in ZIP14- and DMT1-, respectively, but not ZIP8knockdown cells (Fig. 3E). This finding corresponds well with the Cd levels that were lowered only in DMT1- and ZIP14- but not ZIP8-down-regulated cells (Fig. 1D) further demonstrating that the amount of internalized Cd determines MT2A expression levels. Overall, our findings confirm the inducibility of MT2A by Cd in HTR-8/SVneo cells as was previously reported for primary trophoblasts. ${ }^{57}$

In a next step, we wanted to determine whether other MT isoforms can compensate for MT2A depletion. MT1X, the second most common MT isoform in HTR-8/SVneo cells (Fig. 3A) also is inducible by Cd (Fig. S3, ESI $\dagger$ ). However, due to its a priori low constitutive expression, even after Cd treatment MT1X expression does not even reach basal MT2A expression. Overall, none of the analysed MT isoforms seems to be able to compensate for the loss of MT2A (Fig. S3, ESI†). This leaves MT2A as the most potent MT form in defending against Cd toxicity to placental cells.

To verify a protective role of MT2A in placental cells, we analysed cell numbers of Cd-exposed controls and MT2A-knockdown cells (Fig. 4A, B and Fig. S5, ESI†). $5 \mu \mathrm{M}$ Cd exposure for $72 \mathrm{~h}$ decreased cell number to $60 \%$, which corresponds well to findings from a previous report. ${ }^{43}$ The effect was worsened by MT2A depletion,
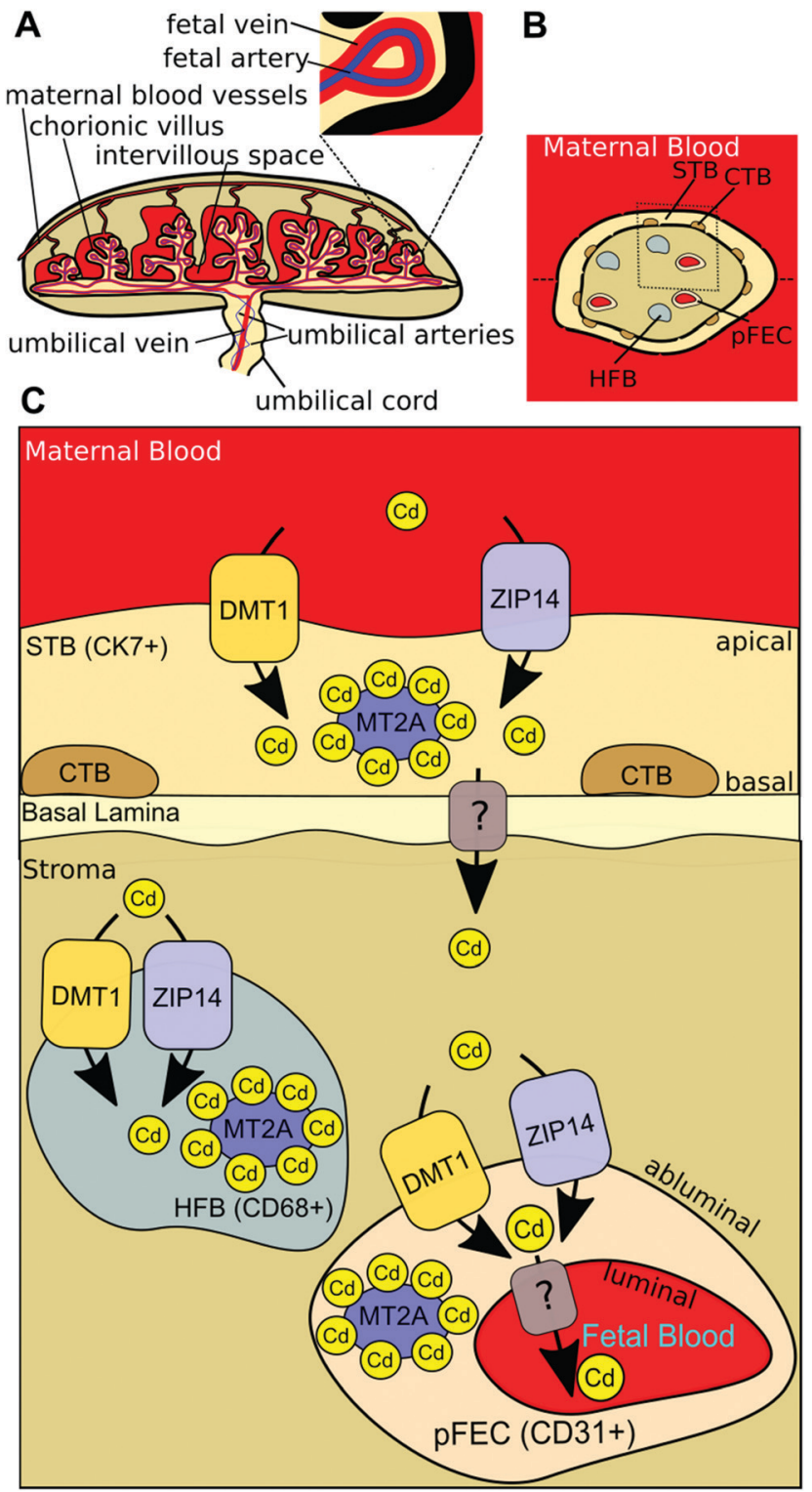

Fig. 5 Model of placental Cd transport. (A) Maternal blood flows from maternal uterine blood vessels into the intervillous space of the human placenta, where it comes in direct contact with the chorionic villi. At this site an exchange of gases and nutrients occurs. Oxygenated, nutrient-rich blood (shown in red) comes over the umbilical vein (branches at junction of umbilical cord and placenta to form fetal veins) from the placenta to the fetus. Deoxygenated, nutrient-depleted blood (shown in blue) goes from the fetus over the two umbilical arteries (branches at junction of umbilical cord and placenta to form fetal arteries) to the placenta. ${ }^{72}$ (B) Horizontal cross-section of a chorionic villus. The maternal blood is in direct contact with the syncytiotrophoblast (STB), which is adjacent to a layer of cytotrophoblasts (CTBs) that becomes discontinuous in later pregnancy. In the villous stroma fibroblasts (not shown), Hofbauer cells (HFBs) and placental fetal endothelial cells ( $p F E C s$ ) reside. (C) Based on our results from in vitro experiments and in situ localisation, we conclude that $\mathrm{Cd}$ is taken up at the apical site of the STB by DMT1 (and probably also by ZIP14) and either stored in MT2A-complexes or effluxed at the basal membrane by unknown transporter(s). In the placental stroma $\mathrm{Cd}$ uses the same transporters to enter HFBs and pFECS and accumulates there bound to MT2A. Yet unknown transporter(s) mediate the $\mathrm{Cd}$ efflux from pFECs into the fetal blood. 
i.e. the cell number became further reduced to $30 \%$. Importantly, the cytotoxic effect of Cd always was aggravated by MT2A depletion $(38 \%, 30 \%$ and 50\% lower cell numbers when treated with $0.1,1$, and $5 \mu \mathrm{M} \mathrm{CdCl}_{2}$, relative to controls). That loss of MT2A affects cell counts (here: $35 \%$ reduction in comparison to unexposed control cells) has also been reported for human prostatic adenocarcinoma ${ }^{67}$ and endothelial cells. ${ }^{66}$ Next to its role in metal homeostasis and detoxification, MT2A also regulates cell type specific oxidative stress, angiogenesis and cell proliferation as well as cell differentiation, which explains why it is associated with many diseases independent of Cd exposure. ${ }^{68}$ The findings together indicate additive effects of Cd exposure and MT2A function on placental cell numbers. This is also indicated by the LC50 (72 h post treatment) that is $4.04 \mu \mathrm{M} \mathrm{Cd}$ (about $454 \mu \mathrm{g} \mathrm{L}^{-1}$ ) in control cells but $2.91 \mu \mathrm{M}\left(327 \mu \mathrm{g} \mathrm{L}^{-1}\right)$ in MT2A downregulated cells. It should be noted that the $\mathrm{Cd}$ concentrations in maternal blood are in a 1000-fold lower concentration range, i.e. they are about $0.23 \mu \mathrm{g} \mathrm{L}^{-1}(2 \mathrm{nM})$ according to a recent review. ${ }^{69}$ However, chronic $\mathrm{Cd}$ accumulation in the human placenta occurs in vivo over a period of nine months, which could generate Cd levels ${ }^{70}$ able to enhance MT expression.

From the correlation analysis (Fig. 3D) one could also expect that less Cd is accumulated when MT2A expression is reduced. Cells with downregulated MT2A expression, however, show more or less the same Cd content as the control cells (Fig. 4C). This suggests that Cd determines cellular MT2A levels, but MT2A does not affect $\mathrm{Cd}$ levels. A possible explanation could be that $\mathrm{Cd}$ in lack of MT2A binds to other ligands such as glutathione. ${ }^{71}$

\section{Conclusion}

In the present study, we show for the first time that DMT1 and ZIP14 are required for the uptake of Cd into human placental cells. The in situ localisation of DMT1 in the human term placenta, as investigated with a validated antibody, revealed that the protein is localised in the STB as well as in the stromal cells of the chorionic tissue. Our data show that MT2A depletion has little or no effect on cellular Cd levels. However, it is clearly shown that intracellular Cd levels increase MT2A gene expression in HTR-8/SVneo cells in a dose-dependent manner, which protects the cells from the toxicity of the metal. Based on our results from in vitro experiments and in situ localisation we suggest a working model (Fig. 5) and conclude that Cd is taken up at the apical site of the STB by DMT1 and probably ZIP14 and retained as either MT2A-complex or effluxed at the basal membrane by yet unknown transporter(s). In the placental stroma Cd may use the same transporters to enter HFBs and pFECS and accumulate there bound to MT2A. Yet unknown transporter(s) mediate the Cd efflux from pFECs into the fetal blood.

\section{Author contribution}

R. W. and C. G. designed and planned the experiments. R. W., S. G., M. F. conducted the experiments and analysed the data. I. E. and K.G. produced IFM images. P. Y. H. and R. B. performed the antibody validation. I. E., H. Z., M. H. and H. S. assisted in the supervision of the project. R. W. and C. G. wrote the manuscript with the participation of all authors. All authors read and approved the final manuscript.

\section{Conflicts of interest}

There are no conflicts to declare.

\section{Acknowledgements}

This study was supported by NFB (Niederösterreichische Forschungs- und Bildungsgesellschaft) (LifeScience2017, Project No. LS17-008).

\section{References}

1 E. C. Agency, Candidate List of substances of very high concern for Authorisation, https://echa.europa.eu/de/candidatelist-table, accessed August 10, 2020.

2 O. Faroon, A. Ashizawa, S. Wright, P. Tucker, K. Jenkins, L. Ingerman and C. Rudisill, Toxicological Profile for Cadmium, Agency for Toxic Substances and Disease Registry (US), 2012.

3 ATSDR 2019 Substance Priority List, https:/www.atsdr.cdc. gov/spl/index.html, accessed August 10, 2020.

4 G. Schoeters, Scoping documents for 2018 Deliverable Report D 4.2 WP 4 Prioritisation and input to the Annual Work Plan https:/www.hbm4eu.eu/wp-content/uploads/ 2017/03/Deliverable-4.2_-Scoping_documents_for_-2018_v3.1. pdf, accessed August 20, 2020.

5 W. H. Organization, EXPOSURE TO CADMIUM: A MAJOR PUBLIC HEALTH CONCERN, 2019.

6 G. F. Nordberg, Cadmium and health in the 21st Century historical remarks and trends for the future, Biometals, 2004, 17, 485-489.

7 G. F. Nordberg, Historical perspectives on cadmium toxicology, Toxicol. Appl. Pharmacol., 2009, 238, 192-200.

8 J. Parizek, Vascular changes at sites of oestrogen biosynthesis produced by parenteral injection of cadmium salts: the destruction of placenta by cadmium salts, J. Reprod. Fertil., 1964, 7, 263-265.

9 K. Arizono, S. Ota and T. Ariyoshi, Purification of Metallothionein-like Protein in Rat Placenta, Bull. Environm. Contam. Toxicol., 1981, 27, 671-677.

10 M. P. Waalkes, A. M. Poisner, G. W. Wood and C. D. Klaassen, Metallothionein-like proteins in human placenta and fetal membranes, Toxicol. Appl. Pharmacol., 1984, 74, 179-184.

11 D. I. Bannon, R. Abounader, P. S. J. Lees and J. P. Bressler, Effect of DMT1 knockdown on iron, cadmium, and lead uptake in Caco-2 cells, Am. J. Physiol.: Cell Physiol., 2003, 284, C44-C50.

12 T. P. Dalton, L. He, B. Wang, M. L. Miller, L. Jin, K. F. Stringer, X. Chang, C. S. Baxter and D. W. Nebert, Identification of 
mouse SLC39A8 as the transporter responsible for cadmiuminduced toxicity in the testis, Proc. Natl. Acad. Sci. U. S. A., 2005, 102, 3401-3406.

13 Y. Nakamura, K.-i. Ohba and H. Ohta, Participation of metal transporters in cadmium transport from mother rat to fetus, J. Toxicol. Sci., 2012, 37, 1035-1044, DOI: 10.2131/ jts.37.1035.

14 C. Gundacker, J. Neesen, E. Straka, I. Ellinger, H. Dolznig and M. Hengstschlager, Genetics of the human placenta: implications for toxicokinetics, Arch. Toxicol., 2016, 90, 2563-2581.

15 C. Gundacker and M. Hengstschläger, The role of the placenta in fetal exposure to heavy metals, Wien. Med. Wochenschr., 2012, 162, 201-206.

16 S. Satarug, S. H. Garrett, M. A. Sens and D. A. Sens, Cadmium, environmental exposure, and health outcomes, Environ. Health Perspect., 2010, 118, 182-190.

17 A. E. Egger, G. Grabmann, C. Gollmann-Tepekoylu, E. J. Pechriggl, C. Artner, A. Turkcan, C. G. Hartinger, H. Fritsch, B. K. Keppler, E. Brenner, M. Grimm, B. Messner and D. Bernhard, Chemical imaging and assessment of cadmium distribution in the human body, Metallomics, 2019, 11, 2010-2019.

18 M. D. Esteban-Vasallo, N. Aragones, M. Pollan, G. LopezAbente and B. Perez-Gomez, Mercury, cadmium, and lead levels in human placenta: a systematic review, Environ. Health Perspect., 2012, 120, 1369-1377.

19 C. Freire, E. Amaya, F. Gil, M. Murcia, S. Lop, M. Casas, M. Vrijheid, A. Lertxundi, A. Irizar, G. Fernandez-Tardon, R. V. Castro-Delgado, N. Olea, M. F. Fernandez and I. Project, Placental metal concentrations and birth outcomes: The Environment and Childhood (INMA) project, Int. J. Hyg. Environ. Health, 2019, 222, 468-478.

20 J. C. Lau, M. G. Joseph and M. G. Cherian, Role of placental metallothionein in maternal to fetal transfer of cadmium in genetically altered mice, Toxicology, 1998, 127, 167-178.

21 M. Kippler, A. M. Hoque, R. Raqib, H. Ohrvik, E. C. Ekstrom and M. Vahter, Accumulation of cadmium in human placenta interacts with the transport of micronutrients to the fetus, Toxicol. Lett., 2010, 192, 162-168.

22 M. Erboga and M. Kanter, Effect of Cadmium on Trophoblast Cell Proliferation and Apoptosis in Different Gestation Periods of Rat Placenta, Biol. Trace Elem. Res., 2016, 169, 285-293.

23 H. X. Geng and L. Wang, Cadmium: Toxic effects on placental and embryonic development, Environ. Toxicol. Pharmacol., 2019, 67, 102-107.

24 M. Tsuji, E. Shibata, S. Morokuma, R. Tanaka, A. Senju, S. Araki, M. Sanefuji, C. Koriyama, M. Yamamoto, Y. Ishihara, K. Kusuhara, T. Kawamoto, H. Saito, R. Kishi, N. Yaegashi, K. Hashimoto, C. Mori, S. Ito, Z. Yamagata, H. Inadera, M. Kamijima, T. Nakayama, H. Iso, M. Shima, Y. Hirooka, N. Suganuma, T. Katoh and J. E. C. S. Grp, The association between whole blood concentrations of heavy metals in pregnant women and premature births: The Japan Environment and Children's Study (JECS), Environ. Res., 2018, 166, 562-569.
25 M. Kippler, F. Tofail, R. Gardner, A. Rahman, J. D. Hamadani, M. Bottai and M. Vahter, Maternal Cadmium Exposure during Pregnancy and Size at Birth: A Prospective Cohort Study, Environ. Health Perspect., 2012, 120, 284-289. 26 F. Wang, F. Y. Fan, L. Y. Wang, W. Ye, Q. Zhang and S. S. Xie, Maternal Cadmium Levels During Pregnancy and the Relationship with Preeclampsia and Fetal Biometric Parameters, Biol. Trace Elem. Res., 2018, 186, 322-329.

27 T. Jacobo-Estrada, M. Santoyo-Sanchez, F. Thevenod and O. Barbier, Cadmium Handling, Toxicity and Molecular Targets Involved during Pregnancy: Lessons from Experimental Models, Int. J. Mol. Sci., 2017, 18(7), 1590.

28 M. Piasek, M. Blanuša, K. Kostial and J. W. Laskey, Low iron diet and parenteral cadmium exposure in pregnant rats: the effects on trace elements and fetal viability, Biometals, 2004, 17, 1-14.

29 C. M. Gallagher, J. J. Chen and J. S. Kovach, The relationship between body iron stores and blood and urine cadmium concentrations in US never-smoking, non-pregnant women aged 20-49 years, Environ. Res., 2011, 111, 702-707.

30 A. C. Illing, A. Shawki, C. L. Cunningham and B. Mackenzie, Substrate profile and metal-ion selectivity of human divalent metal-ion transporter-1, J. Biol. Chem., 2012, 287, 30485-30496.

31 C. Y. Wang, S. Jenkitkasemwong, S. Duarte, B. K. Sparkman, A. Shawki, B. Mackenzie and M. D. Knutson, ZIP8 Is an Iron and Zinc Transporter Whose Cell-surface Expression Is Upregulated by Cellular Iron Loading, J. Biol. Chem., 2012, 287, 34032-34043.

32 K. Girijashanker, L. He, M. Soleimani, J. M. Reed, H. Li, Z. Liu, B. Wang, T. P. Dalton and D. W. Nebert, Slc39a14 gene encodes ZIP14, a metal/bicarbonate symporter: similarities to the ZIP8 transporter, Mol. Pharmacol., 2008, 73, 1413-1423.

33 J. P. Bressler, L. Olivi, J. H. Cheong, Y. Kim and D. Bannon, Divalent metal transporter 1 in lead and cadmium transport, Ann. N. Y. Acad. Sci., 2004, 1012, 142-152.

34 H. Ohrvik, E. Tyden, P. Artursson, A. Oskarsson and J. Tallkvist, Cadmium Transport in a Model of Neonatal Intestinal Cells Correlates to MRP1 and Not DMT1 or FPN1, ISRN Toxicol., 2013, 2013, 892364.

35 J. D. Park, N. J. Cherrington and C. D. Klaassen, Intestinal absorption of cadmium is associated with divalent metal transporter 1 in rats, Toxicol. Sci, 2002, 68, 288-294.

36 D. Y. Ryu, S. J. Lee, D. W. Park, B. S. Choi, C. D. Klaassen and J. D. Park, Dietary iron regulates intestinal cadmium absorption through iron transporters in rats, Toxicol. Lett., 2004, 152, 19-25.

37 J. Tallkvist, C. L. Bowlus and B. Lonnerdal, DMT1 gene expression and cadmium absorption in human absorptive enterocytes, Toxicol. Lett., 2001, 122, 171-177.

38 L. He, B. Wang, E. B. Hay and D. W. Nebert, Discovery of ZIP transporters that participate in cadmium damage to testis and kidney, Toxicol. Appl. Pharmacol., 2009, 238, 250-257.

39 K. Somsuan, L. Phuapittayalert, Y. Srithongchai, P. Sonthi, W. Supanpaiboon, W. Hipkaeo and N. Sakulsak, Increased 
DMT-1 expression in placentas of women living in high-Cdcontaminated areas of Thailand, Environ. Sci. Pollut. Res. Int. , 2019, 26, 141-151.

40 C. H. Graham, T. S. Hawley, R. G. Hawley, J. R. MacDougall, R. S. Kerbel, N. Khoo and P. K. Kala, Establishment and Characterization of First Trimester Human Trophoblast Cells With Extended Lifespan, Exp. Cell Res., 1993, 206, 204-211.

41 A. Espart, S. Artime, G. Tort-Nasarre and E. Yara-Varon, Cadmium exposure during pregnancy and lactation: materno-fetal and newborn repercussions of $\mathrm{Cd}(\mathrm{II})$, and Cdmetallothionein complexes, Metallomics, 2018, 10, 1359-1367.

42 Z. Wei, X. Song and Z. A. Shaikh, Cadmium promotes the proliferation of triple-negative breast cancer cells through EGFR-mediated cell cycle regulation, Toxicol. Appl. Pharmacol., 2015, 289, 98-108.

43 T. Zhou, H. Wang, S. Zhang, X. Jiang and X. Wei, S100P is a potential molecular target of cadmium-induced inhibition of human placental trophoblast cell proliferation, Exp. Toxicol. Pathol., 2016, 68, 565-570.

44 C. Balthasar, H. Stangl, R. Widhalm, S. Granitzer, M. Hengstschlager and C. Gundacker, Methylmercury Uptake into BeWo Cells Depends on LAT2-4F2hc, a System L Amino Acid Transporter, Int. J. Mol. Sci., 2017, 18(8), 1730.

45 S. Nemmiche and P. Guiraud, Cadmium-induced oxidative damages in the human BJAB cells correlate with changes in intracellular trace elements levels and zinc transporters expression, Toxicol. In Vitro, 2016, 37, 169-177.

46 L. F. Jorge-Nebert, M. Galvez-Peralta, J. Landero Figueroa, M. Somarathna, S. Hojyo, T. Fukada and D. W. Nebert, Comparing gene expression during cadmium uptake and distribution: untreated versus oral Cd-treated wild-type and ZIP14 knockout mice, Toxicol. Sci, 2015, 143, 26-35.

47 T. H. P. Atlas, SLC39A14 tissue expression placenta, https:// www.proteinatlas.org/ENSG00000104635-SLC39A14/tissue/ placenta, accessed August 10, 2020.

48 C. Cao and M. D. Fleming, The placenta: the forgotten essential organ of iron transport, Nutr. Rev., 2016, 74, 421-431.

49 Y. M. Gao, Y. M. Xu, D. D. Wu, F. Y. Yu, L. Yang, Y. Yao, Z. L. Liang and A. T. Y. Lau, Progressive silencing of the zinc transporter Zip8 (Slc39a8) in chronic cadmium-exposed lung epithelial cells, Acta Biochim. Biophys. Sin., 2017, 49, 444-449.

50 H. Fujishiro, Y. Yano, Y. Takada, M. Tanihara and S. Himeno, Roles of ZIP8, ZIP14, and DMT1 in transport of cadmium and manganese in mouse kidney proximal tubule cells, Metallomics, 2012, 4, 700-708.

51 M. K. Georgieff, J. K. Wobken, J. Welle, J. R. Burdo and J. R. Conner, Identification and localization of divalent metal transporter-1 (DMT-1) in term human placenta, Placenta, 2000, 21, 799-804.

52 J. Bastin, H. Drakesmith, M. Rees, I. Sargent and A. Townsend, Localisation of proteins of iron metabolism in the human placenta and liver, Br. J. Haematol., 2006, 134, 532-543.

53 W. S. Chong, P. C. Kwan, L. Y. Chan, P. Y. Chiu, T. K. Cheung and T. K. Lau, Expression of divalent metal transporter
1 (DMT1) isoforms in first trimester human placenta and embryonic tissues, Hum. Reprod., 2005, 20, 3532-3538.

54 E. Bafaro, Y. T. Liu, Y. Xu and R. E. Dempski, The emerging role of zinc transporters in cellular homeostasis and cancer, Signal Transduction Targeted Ther., 2017, 2(1), 17029.

55 F. Thevenod, J. Fels, W. K. Lee and R. Zarbock, Channels, transporters and receptors for cadmium and cadmium complexes in eukaryotic cells: myths and facts, Biometals, 2019, 32, 469-489.

56 J. S. Scheller, G. W. Irvine and M. J. Stillman, Unravelling the mechanistic details of metal binding to mammalian metallothioneins from stoichiometric, kinetic, and binding affinity data, Dalton Trans., 2018, 47, 3613-3637.

57 J. G. Breen, C. Eisenmann, S. Horowitz and R. K. Miller, Cell-Specific Increases in Metallothionein Expression in the Human Placenta Perfused with Cadmium, Reprod. Toxicol., 1994, 8, 297-306.

58 V. Gunther, U. Lindert and W. Schaffner, The taste of heavy metals: gene regulation by MTF-1, Biochim. Biophys. Acta, 2012, 1823, 1416-1425.

59 N. Thirumoorthy, A. Shyam Sunder, K. Manisenthil Kumar, M. Senthil Kumar, G. Ganesh and M. Chatterjee, A review of metallothionein isoforms and their role in pathophysiology, World J. Surg. Oncol., 2011, 9, 54.

60 D. E. K. Sutherland and M. J. Stillman, The "magic numbers" of metallothionein, Metallomics, 2011, 3, 444-463.

61 G. Jiang, W. Duan, L. Xu, S. Song, C. Zhu and L. Wu, Biphasic effect of cadmium on cell proliferation in human embryo lung fibroblast cells and its molecular mechanism, Toxicol. In Vitro, 2009, 23, 973-978.

62 D. M. Templeton and Y. Liu, Multiple roles of cadmium in cell death and survival, Chem. - Biol. Interact., 2010, 188, 267-275.

63 C. D. Klaassen, J. Liu and B. A. Diwan, Metallothionein protection of cadmium toxicity, Toxicol. Appl. Pharmacol., 2009, 238, 215-220.

64 N. Miura and S. Koizumi, Heavy Metal Responses of the Human Metallothionein Isoform Genes, Pharm. Soc. Jpn., 2007, 127(4), 665-673.

65 R. V. McNeill, A. S. Mason, M. E. Hodson, J. W. F. Catto and J. Southgate, Specificity of the Metallothionein-1 Response by Cadmium-Exposed Normal Human Urothelial Cells, Int. J. Mol. Sci., 2019, 20, 1344.

66 I. A. Schulkens, K. C. Castricum, E. M. Weijers, P. Koolwijk, A. W. Griffioen and V. L. Thijssen, Expression, regulation and function of human metallothioneins in endothelial cells, J. Vasc. Res., 2014, 51, 231-238.

67 T. Susa, M. Iizuka, H. Okinaga, M. Tamamori-Adachi and T. Okazaki, Without 1alpha-hydroxylation, the gene expression profile of 25(OH)D3 treatment overlaps deeply with that of 1,25(OH)2D3 in prostate cancer cells, Sci. Rep., 2018, 8, 9024.

68 X. B. Ling, H. W. Wei, J. Wang, Y. Q. Kong, Y. Y. Wu, J. L. Guo, T. F. Li and J. K. Li, Mammalian Metallothionein2A and Oxidative Stress, Int. J. Mol. Sci., 2016, 17(9), DOI: 10.3390/ijms17091483.

69 M. Kabamba and J. Tuakuila, Toxic metal (Cd, Hg, Mn, Pb) partition in the maternal/foetal unit: a systematic mini - 
review of recent epidemiological studies, Toxicol. Lett., 2020, 332, 20-26.

70 M. Kantola, R. Purkunen, P. Kroger, A. Tooming, J. Juravskaja, M. Pasanen, S. Saarikoski and T. Vartiainen, Accumulation of Cadmium, Zinc, and Copper in Maternal Blood and Developmental Placental Tissue: Differences between Finland, Estonia, and St. Petersburg, Environ. Res., 2000, 83, 54-66.
71 S. H. Oh, S. Y. Lee, C. H. Choi, S. H. Lee and S. C. Lim, Cadmium adaptation is regulated by multidrug resistanceassociated protein-mediated Akt pathway and metallothionein induction, Arch. Pharmacal Res., 2009, 32, 883-891.

72 Y. Wang and S. Zhao, in Vascular Biology of the Placenta, Morgan \& Claypool Life Sciences, San Rafael (CA), 2010, ch 2, Placental Blood Circulation. 